\title{
FORMAÇÃO DOCENTE PARA PRÁXIS INCLUSIVAS SUBSIDIADAS PELO DESENHO UNIVERSAL PARA A APRENDIZAGEM ${ }^{1}$
}

\author{
Jacqueline Lidiane de Soura Prais \\ Celia Regina Vitaliano
}

\section{Resumo}

A formação de professores e a reorganização do ensino são condições essenciais para favorecer práticas pedagógicas inclusivas. Nesse contexto, a proposta de organização curricular do Desenho Universal para a Aprendizagem (DUA) tem sido referenciada para efetivação da educação inclusiva. Esta pesquisa teve o objetivo geral: analisar o desenvolvimento de um processo de formação continuada em serviço baseada no DUA, realizado junto às professoras de uma escola, atuantes nos anos iniciais do ensino fundamental, por meio de uma pesquisa colaborativa visando ao aprimoramento do processo de inclusão de alunos com Necessidades Educacionais Especiais (NEE). Participaram da pesquisa 13 professoras colaboradoras. O método adotado foi a pesquisa colaborativa e a coleta dos dados se deu em quatro etapas: a sensibilização dos participantes, o levantamento das necessidades formativas dos docentes, o desenvolvimento de um programa de formação e, a avaliação final. O tratamento dos dados se deu por meio da análise de conteúdo e de episódios. Foram constatadas contribuições advindas do processo formativo e as mudanças ocorridas nos planos de aulas e nas práticas pedagógicas efetivas das docentes. Evidenciou-se o aprimoramento do trabalho pedagógico desenvolvido pelas docentes, não somente em relação aos alunos com NEE, mas no favorecimento da qualidade do ensino visando a aprendizagem de todos os estudantes.

Palavras-chave: formação de professores; educação inclusiva; prática pedagógica; Desenho Universal para a Aprendizagem; pesquisa colaborativa.

\section{TEACHER TRAINING FOR INCLUSIVE PRAXIS SUBSIDIZED BY UNIVERSAL DESIGN FOR LEARNING ${ }^{2}$}

\begin{abstract}
The teacher training and the reorganization of education are essential conditions for promoting inclusive pedagogical practices. In this context, the proposal of curricular organization of the Universal Design for Learning (UDL) has been referenced for the realization of inclusive education. This research had the general objective: to analyze the development of a process of continuing education in a service based on UDL, carried out with the teachers of a school, working in the initial years of elementary school, through a collaborative research aimed at improving the inclusion process of students with Special Educational Needs (SEN). 13 collaborating teachers participated in the research. The method adopted was collaborative research and data collection took place in four stages: awareness of participants, the survey of teachers training needs, the development of a training programme and the final evaluation. Data were processed through content analysis and episodes. Were found contributions from the formative process and changes in the teacher's lesson plans and effective pedagogical practices were verified. The improvement of the pedagogical work developed by the teachers was evidenced, students with SEN, but in favoring the quality of teaching aimed at learning all students.
\end{abstract}

Keywords: teacher training; inclusive education; pedagogical practice; Universal Design for Learning; collaborative research.

\footnotetext{
${ }^{1}$ O presente trabalho foi realizado com apoio da Coordenação de Aperfeiçoamento de Pessoal de Nível Superior Brasil (CAPES) - Código de Financiamento 001.

2 This study was financed in part by the Coordenação de Aperfeiçoamento de Pessoal de Nível Superior - Brasil (CAPES) - Finance Code 001
} 


\section{FORMACIÓN DEL PROFESORADO PARA PRAXIS INCLUSIVAS SUBVENCIONADA POR EL DISEÑO UNIVERSAL PARA EL APRENDIZAJE ${ }^{3}$}

\section{Resumen}

La formación del profesorado y la reorganización de la educación son condiciones esenciales para promover prácticas pedagógicas inclusivas. En este contexto, se ha hecho referencia a la propuesta de organización curricular del Diseño Universal para el Aprendizaje (DUA) para la realización de una educación inclusiva. Esta investigación tuvo el objetivo general: analizar el desarrollo de un proceso de formación continua en el servicio basado en DUA, realizado con los profesores de una escuela, trabajando en los primeros años de la escuela primaria, a través de una investigación colaborativa dirigida a mejorar el proceso de inclusión de los estudiantes con Necesidades Educativas Especiales (NEE). 13 profesores colaboradores participaron en la investigación. El método adoptado fue la investigación colaborativa y la recopilación de datos se llevó a cabo en cuatro etapas: sensibilización de los participantes, la encuesta de las necesidades de formación de los profesores, el desarrollo de un programa de capacitación y la evaluación final. Los datos se procesaron a través del análisis de contenido y episodios. Se verificaron las contribuciones del proceso formativo y los cambios que ocurrieron en los planes de los profesores y en las prácticas pedagógicas efectivas. La mejora del trabajo pedagógico desarrollado por los profesores se evidió, no sólo en relación con los estudiantes con NEE, sino en favorecer la calidad de la enseñanza dirigida al aprendizaje de todos los estudiantes.

Palabras clave: formación del profesorado; educación inclusiva; práctica pedagógica; Diseño Universal para el Aprendizaje; investigación colaborativa.

\section{INTRODUÇÃO}

A inclusão educacional se baseia na implementação de ações que visam assegurar o direto de todos à educação (UNESCO, 1994). No Brasil, este direito foi fixado na sétima Constituição Federal, país este que enfrentou e enfrenta o desafio de legitimar este direito nas escolas (BRASIL, 1988).

Percebemos que a proposta de implementação da educação inclusiva desencadeou inúmeras preocupações e inquietações para sua efetivação, para além das intenções legais. A inclusão educacional representa, em linhas gerais, um desafio para o sistema de ensino brasileiro. Em outras palavras, mesmo havendo o reconhecimento do direito de todos à educação, tendo uma legislação que o assegura, sua consolidação plena não se efetiva (LUSTOSA, 2019).

Um dos pontos que dificultam este processo de assegurar o direito de todos à educação é a carência nos modos formativos, pois estes parecem não surtir efeito para mobilizar os professores para o aprimoramento da prática pedagógica inclusiva, promovendo adequações no contexto educacional. Tal premissa corrobora com os estudos desenvolvidos na área da formação docente para a inclusão educacional (ROSA, 2019; SANCHES, 2011). Tais pesquisas evidenciam que a formação docente vem sendo insuficiente para favorecer o desenvolvimento de práticas pedagógicas condizentes com os princípios inclusivos (PRAIS, 2017).

Portanto, enfatizamos ser urgente uma formação pedagógica dos professores pensada na e para a inclusão escolar (CAPELLINI, FONSECA, 2017; HEREDERO, 2018; VITALIANO, 2019). De tal modo, esclarecemos que admitimos nesta pesquisa como professores, todos os docentes que atuam na escola, sendo aqueles que estão em sala de aula, que estão na equipe

\footnotetext{
${ }^{3}$ Este trabajo se llevó a cabo con el apoyo de la Coordinación de Perfeccionamiento del Personal de Educación Superior - Brasil (CAPES) - Código de Financiamiento 001.
} 
pedagógica sejam como orientador ou supervisor ou pedagogo, e ainda os que estão na gestão escolar (diretor).

Dado esse contexto, esta pesquisa foi motivada pelo interesse em desenvolver um processo de formação continuada em serviço de professores atuantes nos anos iniciais do ensino regular visando aprimorar a forma que realizavam seu planejamento de ensino e a sua prática pedagógica junto aos alunos com NEE, por meio da aplicação dos princípios do Desenho Universal para a Aprendizagem (DUA).

Com base nessa perspectiva, a formação continuada ganha destaque ao conseguir responder, mais rapidamente, às demandas e aos desafios enfrentados diante da diversidade e/ou complexidade do cotidiano escolar (HEREDERO, 2018). Nesse sentido, a formação continuada deve ser concebida como um momento de possibilidade para a reelaboração dos saberes iniciais em confronto com as experiências práticas do dia-a-dia do professor e de novas práticas pedagógicas.

O DUA representa uma possibilidade curricular adequada e necessária na formação e na prática dos professores visando a inclusão educacional (PRAIS, 2017; HEREDERO, 2018). Essa abordagem começou a ser delineada na década de 1990 por Anne Meyer, David Rose e David Gordon. Essa perspectiva propõe um desenho didático curricular para o planejamento docente em uma perspectiva inclusiva a partir da remoção de barreiras para o acesso ao currículo escolar. Pressupomos que o ensino deve ser organizado a partir da flexibilidade e da acessibilidade para a aprendizagem, a fim de que um maior número de alunos aprenda (MEYER, ROSE, GORDON, 2002).

Desse modo, o conceito acessibilidade relacionado a um local/espaço foi redimensionado para o processo de ensino, em que haja acesso à aprendizagem. Esse conceito assume que, mais do que intenções, são necessárias práticas inclusivas que efetivem os princípios de um ensino para assegurar a aprendizagem dos alunos, bem como satisfaça as necessidades educacionais dos alunos. Para Marin e Braun (2020, p. 14) a finalidade da proposta curricular do DUA "[...] é o desenvolvimento de práticas pedagógicas que permitam o acesso ao currículo, a participação e o progresso de todos os alunos, independentemente das suas capacidades". Dessa forma, as autoras supracitadas afirmam que o "currículo em ação" poderá atender as diferenças e as necessidades de todos os estudantes e “[...] os obstáculos pedagógicos serão removidos para que haja acessibilidade curricular" (MARIN, BRAUN, 2020, p. 14).

Por isso, a diferenciação curricular nesta proposta pressupõe a promoção de equidade, e frisa a importância do currículo pensado de forma mais flexível, aberto às diferenças, orientado pelas singularidades dos estudantes e não pelas impossibilidades impostas ao processo de aprendizagem (MARIN, BRAUN, 2020).

Percebemos que o DUA assume como princípios norteadores: possibilitar múltiplas formas de apresentação do conteúdo, de ação e expressão do conteúdo pelo aluno, proporcionar vários modos de aprendizagem e desenvolvimento organizados pelo professor para os alunos e promover a participação, o interesse e o engajamento na realização das atividades pedagógicas (CAST, 2011).

Estes princípios do DUA assumem objetivos e estratégias para uma proposta didática de ensino, que visa a satisfazer as necessidades de aprendizagem de um maior número de alunos em sala de aula. Consequentemente, a organização do ensino direcionado à aprendizagem de todos os alunos encontra, nos princípios do DUA a possibilidade de o movimento da inclusão escolar ser consolidado (MEYER, ROSE, GORDON, 2014). Conforme Heredero (2018), o DUA consiste em um marco no que tange as discussões concernente ao currículo inclusivo pensado a partir do objetivo de remover barreiras que impedem o acesso a ele. 
A partir disso, o problema deste estudo constituiu na seguinte questão: de que maneira um processo de formação continuada em serviço baseado nos princípios do DUA, realizado junto às professoras de uma escola regular, por meio de uma pesquisa colaborativa, poderia favorecer o aprimoramento do processo de inclusão dos alunos com NEE?

Considerando tal problema, derivamos como objetivo geral: analisar o desenvolvimento de um processo de formação continuada em serviço baseada no DUA, realizado junto às professoras de uma escola, atuantes nos anos iniciais do Ensino Fundamental, por meio de uma pesquisa colaborativa visando ao aprimoramento do processo de inclusão de alunos com Necessidades Educacionais Especiais (NEE).

\section{MÉTODO}

O estudo foi desenvolvido a partir das etapas da pesquisa colaborativa, conforme Ibiapina (2008). Segundo a autora este tipo de estudo envolve três aspectos principais: a colaboração, os círculos reflexivos e a coprodução de conhecimentos entre os pesquisadores e os professores.

Este tipo de investigação aproxima a produção de saberes e a formação contínua de professores por meio da pesquisa contemplando questões práticas e teóricas desencadeando processos de estudos frente aos problemas e as necessidades do agir profissional no contexto escolar (IBIAPINA, 2008).

A pesquisa contou com o envolvimento colaborativo de 13 professoras que atuavam nos anos iniciais do ensino fundamental em uma escola pública e municipal localizada em uma cidade do Norte do Paraná que atendeu, em média, 122 alunos no ano de 2019, a saber:

Tabela 1: Codificação das professoras colaboradoras

\begin{tabular}{|c|l|}
\hline Identificação & \multicolumn{1}{|c|}{ Docentes } \\
\hline PD & Professora diretora \\
\hline PO & Professora orientadora \\
\hline OS & Professora supervisora \\
\hline PSRM - T1 & Professora da Sala de Recursos Multifuncionais - Tipo 1 \\
\hline PA & Professora de Arte \\
\hline PEF & Professora de Educação Física \\
\hline P2A & Professora do $2^{\circ}$ ano A \\
\hline P2B & Professora do $2^{\circ}$ ano B \\
\hline P3A & Professora do $3^{\circ}$ ano A \\
\hline P3B & Professora do $3^{\circ}$ ano B \\
\hline P4A & Professora do $4^{\circ}$ ano A \\
\hline P5A & Professora do $5^{\circ}$ ano A \\
\hline PAP & Professora de Apoio \\
\hline
\end{tabular}

Fonte: Elaborada pelas autoras (2019)

As 13 docentes eram do sexo feminino, com idades que variavam entre 23 anos a 57 anos, e o tempo de experiência variou de um ano a 22 anos. Cabe ressaltar que a P3A estava em seu primeiro ano de atuação como docente. $\mathrm{Na}$ época da coleta havia 12 discentes público-alvo da educação especial (PAEE) matriculados, dois do sexo masculino e dez do sexo feminino, sendo 
que seis receberam atendimento educacional especializado na SRM - Tipo 1 da escola e um atendimento em um centro especializado na cidade e, os demais, eram atendidos no projeto de atendimento de reforço escolar oferecido na escola pela equipe pedagógica. Os alunos possuíam diagnóstico de Transtorno do Déficit de Atenção e Hiperatividade (7), Transtorno Específico de Aprendizagem (1), deficiência intelectual (3), deficiência auditiva (1), Transtorno Opositor Desafiador (1), Transtorno do Humor (1), dislexia (1), Transtorno do Desenvolvimento Intelectual (1) e Transtorno do Espectro Autista (1).

Durante o ano letivo de 2019, 16 alunos foram acompanhados por seus respectivos professores da classe comum e equipe pedagógica com apoio da equipe de educação especial da SEMED, visando identificar e avaliar suas necessidades de aprendizagem, denominados de alunos em processo de avaliação (APA). Os alunos encaminhados apresentavam déficits de atenção e dificuldades de reter os conteúdos.

Como procedimentos metodológicos a pesquisa foi desenvolvida em quatro etapas: i) sensibilização dos participantes, ii) levantamento das necessidades formativas; iii) processo de formação colaborativa envolvendo as estratégias de ciclo de estudos, participação colaborativa, prática reflexiva e planejamento colaborativo, sendo as três últimas realizadas com P2A, P2B, P4A, e P5A; e, por fim, iv) avaliação do processo de formação colaborativa. A pesquisa foi aprovada pelo Comitê de Ética em Pesquisa pelo Parecer n. 3.079.090. A coleta de dados foi realizada entre os meses de fevereiro a dezembro do ano de 2019.

Tabela 2: Síntese dos objetivos, procedimentos e tratamento dos dados realizados em cada fase da pesquisa

\begin{tabular}{|c|c|c|}
\hline Fases da pesquisa & Período & Número de encontros / Procedimentos \\
\hline $\begin{array}{l}\text { Fase } 1 \text { - } \\
\text { Sensibilização }\end{array}$ & Fevereiro & $\begin{array}{l}1 \text { Reunião com a gestão escolar e equipe } \\
\text { pedagógica } \\
1 \text { Reunião coletiva } \\
5 \text { Conversas individuais e/ou grupos para } \\
\text { esclarecimentos } \\
1 \text { Momento de assinatura do TCLE }\end{array}$ \\
\hline $\begin{array}{l}\text { Fase } 2 \text { - } \\
\text { Levantamento das } \\
\text { necessidades } \\
\text { formativas }\end{array}$ & Fevereiro e março & $\begin{array}{l}1 \text { Análise do Projeto Político Pedagógico } \\
16 \text { Observações em sala de aula } \\
16 \text { Análise do planejamento de ensino } \\
13 \text { Entrevistas individuais }\end{array}$ \\
\hline $\begin{array}{l}\text { Fase } 3 \text { - Processo } \\
\text { de formação }\end{array}$ & Abril a novembro & $\begin{array}{l}16 \text { Ciclos de estudos } \\
94 \text { Práticas reflexivas } \\
184 \text { Planejamento colaborativo } \\
94 \text { Participação colaborativa da pesquisadora em } \\
\text { sala de aula }\end{array}$ \\
\hline $\begin{array}{l}\text { Fase } 4 \text { - Avaliação } \\
\text { do processo de } \\
\text { formação }\end{array}$ & Dezembro & $\begin{array}{l}1 \text { Reunião coletiva } \\
12 \text { Análise do planejamento de ensino } \\
13 \text { Entrevistas individuais } \\
12 \text { Observação sem intervenção em sala de aula } \\
\text { e no contexto }\end{array}$ \\
\hline
\end{tabular}

Fonte: Elaborada pelas autoras (2019)

Em relação às estratégias formativas desenvolvidas na Fase 3, esclarecemos que: 
a) Ciclos de estudos: foram realizados quinzenalmente com duração de uma hora e meia envolvendo a participação de todas as professoras colaboradoras em estudos de textos e de situações vivenciadas em sala de aula.

b) Práticas reflexivas: foram analisadas as formas didáticas, por meio das quais as professoras desenvolveram as atividades pedagógicas em sala de aula, com duração de uma hora semanalmente, de modo individualizado.

c) Planejamento colaborativo: foram realizados 94 encontros, durante o período de duas horas por semana, com cada docente, separadamente, que resultaram na elaboração de planos de aula colaborativos subsidiados pelos princípios do DUA.

d) Participação colaborativa: foram desenvolvidas no mínimo duas horas semanalmente com cada uma delas (P2A, P2B, P4A e P5A), visando o aprimoramento do trabalho pedagógico em sala de aula a partir da proposta do DUA e na execução dos planos de aula.

Foram utilizados como instrumentos de coleta de dados: notas de campo, roteiros de entrevistas, protocolo de registro das observações em sala de aula, roteirização para a análise do planejamento, roteirização para o planejamento colaborativo e, ferramenta com questões norteadoras para as práticas reflexivas.

Para análise dos dados definimos como técnica a análise de conteúdo (BARDIN, 2011) e dos episódios (MOURA, 2004) que permitiram a organização dos dados em quatro categorias: i) análise dos dados da Fase 1: sensibilização dos participantes; ii) análise dos dados da Fase 2: necessidades formativas; iii) análise dos dados da Fase 3: processo de formação colaborativa; iv) análise dos dados da Fase 4: avaliação do processo de formação, apresentadas e discutidas a seguir.

\section{RESULTADOS E DISCUSSÃO}

\section{Análise dos dados da Fase 1: sensibilização dos participantes}

Dentre os aspectos que envolvem a qualidade de um processo de formação, está o interesse das professoras colaboradoras pelo tema formativo (SANCHES, 2011). De tal modo, ao apresentar o tema deste estudo ressaltamos que todas elas demonstraram interesse pela formação, ao ponto que, as treze que atuavam nos anos iniciais do ensino fundamental, aceitaram o convite e participaram do programa de formação, sem haver desistência durante o processo.

As professoras colaboradoras admitiram a necessidade de estudar sobre este tema e de aprimorar a prática pedagógica no contexto regular de ensino, tendo em vista as especificidades apresentadas pelos alunos com NEE.

Sublinhamos que, na apresentação da proposta na escola, fomos recebidos pela diretora e, que ela fez questão de que a equipe pedagógica se fizesse presente na conversa inicial. Tal episódio representou a articulação entre os profissionais da instituição com vista a conhecer a proposta do programa de formação que seria oferecido e, evidenciou o quanto a equipe pedagógica atuava de modo cooperativo nas ações pedagógicas da escola.

O fato de a equipe pedagógica e de a gestão escolar demonstrarem engajamento pedagógico corrobora com o envolvimento dos demais membros da escola, para a formação docente e para a mudança dentro do contexto escolar (VITALIANO, 2019).

\section{Análise dos dados da Fase 2: necessidades formativas}

Evidenciamos nos dados coletados quatro temas pertinentes aos objetivos da pesquisa que se constituíram nas necessidades formativas das participantes, alvos do processo de formação: a) concepção de educação inclusiva; b) formação para a organização das práticas pedagógicas junto 
aos alunos com NEE; c) planejamento do ensino; d) prática pedagógica, sendo que estes temas foram validados pelas docentes em uma reunião coletiva e reflexiva, na qual foi apresentada uma síntese dos dados coletados.

Observamos nos relatos das professoras colaboradoras certa carência conceitual para definir educação inclusiva, bem como, uma visão negativa desta perspectiva. Para P4A, a educação inclusiva era colocar os alunos com deficiência na sala de aula. PA considerava a inclusão uma utopia e P5A questionou se esse é o caminho, e ambas reconheceram que era preciso melhorar as condições pedagógicas para se efetivar a inclusão. Nesses exemplos supracitados, identificamos uma visão simplista sobre educação inclusiva, ao mesmo tempo em que identificaram dificuldades e a necessidade de aprimoramento. Desse modo, compreendemos que a visão destas docentes revelou a falta de conhecimento e despreparo diante do conceito de inclusão educacional. Elas apontaram limitações para se efetivar a Educação inclusiva na escola, entre elas a carência de conhecimentos sobre esse tema por parte da gestão escolar e da equipe pedagógica para oferecer suporte e orientação. Além disso, perceberam que, em alguns momentos, a escola não atendia às necessidades do aluno e exigia que ele se adaptasse ao que era proposto para turma, aliada à constatação de que ele não estava aprendendo.

A falta do suporte formativo foi percebida pelas docentes, que ao desconhecerem possibilidades no planejamento e a falta de domínio do conteúdo incorria na insegurança para satisfazer às necessidades de aprendizagem dos alunos com NEE. Nessa perspectiva, elas declararam não terem recebido informações ou formação suficiente para realizar atividades diferenciadas e organizar sua prática pedagógica visando à aprendizagem de todos.

A partir da análise dos planejamentos em confronto com as observações e com os relatos das professoras colaboradoras, identificamos algumas dificuldades no próprio ato de planejar e de registrar as atividades que seriam desenvolvidas, na escolha dos encaminhamentos e do tipo de tarefa para aquele conteúdo e turma, bem como, falta de domínio do conteúdo a ser ensinado aos alunos.

As docentes que atuavam dentro das classes comuns com os alunos com NEE, informaram que até o momento, não haviam realizado adequação, adaptação ou diferenciação curricular para atender às necessidades dos alunos com NEE, bem como, nenhuma delas possuía conhecimento a respeito da abordagem curricular apresentada pelo Desenho Universal para a Aprendizagem (DUA).

Evidenciamos que as professoras colaboradoras não registravam no planejamento esse trabalho diferenciado, os níveis diferentes de exigência da mesma atividade ou os encaminhamentos para o processo de inclusão dos alunos com NEE. Segundo a PS, não havia uma exigência desse registro e o desenvolvimento de atividades pedagógicas de modo diferenciado dependia de cada professor e, um processo de adaptação curricular nunca foi feita na instituição.

Observamos, nas aulas desenvolvidas pelas professoras colaboradoras, certa repetição dos encaminhamentos metodológicos voltados a todos os alunos. A acomodação deles em fileiras foi a maneira mais frequente de dispô-los durante as observações. Na apresentação dos conteúdos, elas priorizaram a explicação oral e o registro no quadro. Para a checagem da aprendizagem pelos discentes, era solicitada a escrita no caderno para realização das atividades propostas. E, no caso de estratégias de engajamento, durante o desenvolvimento das tarefas, houve o predomínio do encorajamento verbal e acompanhamento individual para realização e verificação do cumprimento da atividade.

Identificamos nas observações e nos relatos das professoras colaboradoras, a preocupação com a ausência de um professor de apoio em sala de aula para auxiliá-las no atendimento às dificuldades dos alunos com NEE. De tal modo, elas demonstraram desconhecimento sobre o 
processo de avaliação das necessidades de aprendizagem, bem como desconhecimento sobre os casos que têm assegurado o direito de ter um professor de apoio à aprendizagem dentro da classe comum. Somado a isso, percebemos que as professoras colaboradoras atribuíam a dificuldade de aprendizagem dos alunos à sua própria falta de atenção e à falta de apoio e, não refletiam sobre a possibilidade de desenvolverem práticas pedagógicas que pudessem motivá-los.

Evidenciamos que a avaliação para as docentes desta pesquisa se resumia em interpretar se o aluno com NEE aprendeu ou não, tendo como fonte a atividade proposta realizada ou não por ele. De tal modo, esta ação avaliativa era desprovida da interpretação das dificuldades dos alunos em relação ao seu contexto de aprendizagem e o nível de habilidades que apresentavam, bem como das estratégias utilizadas por ele para tentar resolver a atividade, entre outros aspectos que poderiam ser observados em sala de aula.

Tais práticas escolares que identificamos nas entrevistas, nas observações e nos planejamentos de ensino das professoras colaboradoras, nos mobilizaram a se apoderar de conhecimentos que aprimorassem a formação delas, visando minimizar a existência dessas negligências no processo de inclusão de aluno com NEE da instituição participante desta pesquisa.

Análise dos dados da Fase 3: processo de formação colaborativa

Nessa fase foram desenvolvidos os ciclos de estudos, participação colaborativa, prática reflexiva e planejamento colaborativo, sendo os três últimos procedimentos realizados apenas com P2A, P2B, P4A e P5A. Ao propiciar as oportunidades de estudos teóricos acerca dos temas considerados relevantes para o grupo de docentes, foi fortalecido o espírito colaborativo do grupo, visto que nos ciclos de estudos elas comentaram sobre a importância de discutirem os temas juntas e apoiarem umas às outras em suas dúvidas.

Quando estudamos sobre a organização da prática pedagógica que tem como ponto de partida o reconhecimento da diversidade em sala de aula, P2A recordou o texto estudado, no início do Ciclo de estudos, sobre a educação inclusiva que explicava que a diversidade é uma oportunidade (DÍEZ, 2010).

\section{Episódio 1: Diálogo reflexivo no Ciclo de Estudos - 24/06/2019}

P2A: Mas olha lá para você ver "a diversidade é uma oportunidade" é outro item que estudamos naquele texto lá no início. Lembram? Gente, aprendo tanto com eles. Fico louquinha (risos), mas nossa é uma aprendizagem cada dia. E aí a gente vê que não viu tudo nessa vida.

P5A: Nossa, isso é verdade. Precisei de um tempo para conhecer e reconhecer minha aluna em sala. É muito diferente. É até errado falar, mas gente às vezes a gente perde a paciência. Aí parece que o negócio não vai. São muitos alunos na sala. Está bem difícil, mas acho que estamos caminhando, um passo de cada vez.

Fonte: Notas de campo com falas transcritas (2019)

Os momentos formativos nos ciclos de estudos culminaram em possibilidades de uma análise teórica das situações do dia a dia, ao mesmo tempo em que permitiu às professoras colaboradoras um distanciamento suficiente para pensar em suas práticas pedagógicas, fonte de pesquisa e de intervenção. Tais estudos qualificaram tanto a percepção sobre as ações educativas de cada uma delas quanto ao entendimento dos pressupostos da educação inclusiva, bem como, o papel de delas nesse contexto. De tal modo, percebemos que todas desenvolveram consciência sobre a importância de estarem comprometidas com a construção de uma escola inclusiva, visando propiciar condições para favorecer a aprendizagem de todos os alunos. Houve participação ativa 
de todas elas, pois realizaram as leituras do texto com antecedência, destacavam partes do texto que julgaram importantes e anotaram dúvidas.

Nas práticas reflexivas, as docentes tiveram a oportunidade de refletir criticamente sobre suas práxis pautadas nos estudos e nas vivências em sala de aula. Essa organização formativa possibilitou mudanças na ação pedagógica por meio do entendimento dos pressupostos da educação inclusiva e dos princípios do DUA.

\section{Episódio 2: Prática reflexiva com P4A - 03/10/2019}

P: E, pensando em tudo que conversamos em sala, e hoje aqui, o que você mudaria em suas atividades para a inclusão do aluno PAEE? Você faria algo diferente no sentido de motivar o aluno PAEE para aprender?

P4A: Sim, sempre é possível. Então, preciso me organizar. É tanta coisa. Sempre surge uma coisa diferente. Então, já percebi que quando eu sento, estudo, penso certinho a aula flui mais. E estava muito insegura no começo, tudo novo para mim, essas alunas mesmo, nunca tinha trabalhado assim com base no DUA. Então, preciso explicar melhor a atividade. Tenho que me organizar para pensar certinho como aplicá-la, aquela parte no começo da aula. Porque quando eu consigo fazer o plano do DUA já fica diferente, eles participam mais, se envolvem mais, participam mais, sabe. Então, acho que assim eles já se envolvem mais, não preciso ficar chamando tanto atenção e as meninas também sabe?

P: Sim, é o que temos visto nos nosso ciclo de estudos, outros professores também comentando, não é mesmo essa questão de organizar, de planejar. É trabalhoso quando nos propomos a investir na educação inclusiva, na aprendizagem dos nossos alunos. Mas, essa é a nossa função não é mesmo? Ensinar para eles aprenderem? Se não estariam nos contos da dona carochinha. Entendo que são várias áreas do conhecimento, são quatro dias na semana para trabalhar os conteúdos e um dia para planejar que acaba sendo pouco, mas nesse pouco é preciso sentar e esquematizar o que será trabalhado para depois, poder pensar de maneira mais adequada as atividades, o desenvolvimento da aula.

P4A: Sim é pouco tempo, e como trabalho em outra escola a tarde. Aí não tenho muito tempo em casa. Mas, o DUA ajudou bastante. A P5A é sempre muito colaboradora, partilha ideia de atividades comigo. Ela é bem bacana. Tem me ajudado muito. Aquela questão de apresentar o conteúdo de maneiras diferentes. Sabe uma coisa, primeiro planejar mais, e levar mais recursos para sala, lembra da fração que a PS me mostrou, foi simples, mas super legal. E outra coisa é colocar a PAEE8 mais para frente de novo, porque ela fica lado da estagiária no fundo não consigo ir toda hora lá. É porque desse modo consigo também ver se ela está fazendo ou não sozinha, ou se a estagiária estava falando para ela o que tinha que fazer, né.

Fonte: Notas de campo da pesquisadora (2019)

Nesta reflexão, P4A foi mobilizada a repensar sua prática e a importância do planejamento na promoção da inclusão dos alunos com NEE. A professora colaboradora reconheceu que quando organizou seu plano de aula, subsidiados pelos princípios do DUA favoreceu maior envolvimento e aprendizagem das alunas PAEE8, PAEE9 e PAEE10.

Nas ocasiões dos planejamentos das aulas junto às professoras colaboradoras nos deparamos com situações inesperadas. Algumas delas apresentaram falta de domínio dos conteúdos curriculares a serem trabalhados, desconhecimento de diferentes estratégias de ensino e recursos didáticos. Sublinhamos que a elaboração dos planos de aulas foram momentos de intensas pesquisas e emergiu a necessidade de retomar conteúdos que, inicialmente, não tinham sido previstos na pesquisa, aliado ao trabalho de construir, de modo colaborativo, os planejamentos de acordo com os princípios do DUA. Apresentamos a seguir um diálogo com P5A para exemplificar questões que lhe geraram dúvidas ao realizar o planejamento de uma aula com base no DUA. 


\section{Episódio 3: Planejamento colaborativo com P5A}

P5A: P queria aproveitar para tirar uma dúvida. Nessa aula aqui, sobre células ok? Ciências. Escrevi aqui, uso do livro, tem bastantes imagens lá, montaríamos um mapa mental com as ideias do texto, e tal, tem mais coisas, mas minha dúvida é: depois de estudar em sala, quero pedir para eles montarem em casa uma célula, usando recursos diversos, podendo ser massinha, desenho mesmo à mão, tampinha de garrafa, papelão, o que eles verem pela frente, aqui da escola foi dar algumas opções mesmo. Aí, essa atividade para eles fazerem em casa. Posso contar aqui no plano que é uma forma de ação e representação e uma estratégia para o engajamento mesmo não sendo uma atividade na sala?

P: Claro que sim. A aula não é somente dentro da sala, entre quatro paredes, não é mesmo? Toda atividade faz parte do seu ensino e da aprendizagem do aluno. E essa atividade é muito interesse irá mobilizar aos alunos a buscarem recursos para representarem uma célula, o que eles estudaram na sala. P5A: Sim, pensei nisso sabe. Eles pedem mais do que na sala, e eles gostam dessas coisas feitas por eles.

Fonte: Notas de campo da pesquisadora (2019)

P5A demonstrou neste momento de planejamento colaborativo que estava considerando os princípios do DUA para elaborar suas aulas. Somado a isso, a docente revelou estar considerando subsídios inclusivos para sua prática pedagógica percebendo as características da turma e buscou propor uma atividade que despertasse o interesse e o engajamento dos alunos.

Constatamos que as atividades desenvolvidas em sala de aula, subsidiadas nos princípios DUA visando o desenvolvimento de práticas pedagógicas inclusivas, culminaram em um enfrentamento diário dos desafios vivenciados por cada professor com sua turma e com cada um de seus alunos. Por sua vez, o apoio empreendido durante a implementação das ações didáticas para o atendimento às necessidades de aprendizagem dos alunos baseadas no DUA possibilitou o trabalho colaborativo desde a identificação de aspectos que favoreciam ou não o ensino voltado às necessidades de todos os alunos, como no aprimoramento do planejamento e das práticas desenvolvidas por cada uma das docentes.

Assim, a reestruturação da escola e/ou sua reorganização dependem da construção de uma cultura colaborativa e inclusiva na qual o professor pode pensar e elaborar o ensino e as estratégias em conjunto com profissionais qualificados, dentre eles o professor da educação especial, (CAPELLINI, FONSECA, 2017), que nesta pesquisa estava representado pelo trabalho conjunto com a pesquisadora e especialista nesta área.

Com base nesses pressupostos, após aplicação de um plano de aula na prática pedagógica, P2A declarou que os alunos com NEE conseguiram realizar as atividades propostas de forma mais independente, sublinhando que PAEE1 auxiliou colegas a indicarem sua posição na planta baixa, se propôs a auxiliar a professora durante a construção da legenda e da planta baixa e apresentou, oralmente, uma aprendizagem do conceito condizente aos objetivos previstos para aula.

P2A: Essa aula mostrou para mim o quanto é importante essa construção do conceito ao longo da aula. Foi muito bom para turma toda, ir passo a passo construindo, primeiro o que tem na sala, depois a legenda foi muito boa construir com eles, e em seguida montar com eles a planta. Se eu tivesse levado pronta, apenas para mostrar o que é uma planta baixa, aposto que não faria sentido. E a realização dessa atividade foi além do que eu imaginei, ele discutindo, não essa janela é mais para cá, porque a porta fica mais para cá. Uma noção de espaço surpreendente, inclusive aqueles com NEE foram os que mais surpreenderem. A fala deles é muito boa, por isso múltiplas formas, né. Porque se fosse só escrita eles não iam conseguir fazer sozinhos, e não iam entender nada. 
Interpretamos que P2A indicou que o processo de planificação do conteúdo (materializado no cartaz com a planta baixa) favoreceu o engajamento dos alunos e múltiplas formas de apresentação do conteúdo e de ação e expressão de aprendizagem pelos alunos. Somado a isso, a professora-colaboradora indicou que a atividade satisfez às NEE apresentadas por seus alunos, durante as possibilidades didáticas que foram propiciadas. Conforme a proposta do DUA, são essas possibilidades que revelam que, comumente, a dificuldade não está fixada no aluno, mas nos caminhos que são oferecidos a eles para aprenderem e terem acesso à aprendizagem (NUNES; MADUREIRA, 2015). No momento que o professor consegue encontrar um caminho possível para aprendizagem do aluno, ela acontece.

$\mathrm{Na}$ sequência apresentamos a percepção da professora do $5^{\circ}$ ano após a implementação do plano de aula, elaborado colaborativamente com a pesquisadora, em sua prática pedagógica frente à aplicação dos princípios do DUA. Em específico a professora relata os efeitos de seu planejamento, no qual utilizou texto ilustrado do livro didático, esquemas e construção de mapa mental em pequenos grupos, construção em etapas de um protótipo do sistema respiratório pelos alunos de modo individual, explicação oral com apoio visual.

P5A: Quando você falou para gente lá no ciclo de estudos de planificação, nossa achei que nossa como foi fazer isso. Deve ser muito difícil. Mas não, quando conhecemos os princípios do DUA, na hora já começa a vir umas ideias, algo que já vi, ou soube que alguém já fez diferente, sabe? Algo que dá para ver pela internet, algum experimento para adaptar para eles. Aí gente ficar só no livro para explicar esses conteúdos do corpo humano fica tão maçante. E olha que o livro tem imagem ótimas. Mas é muito bom, fazer essa planificação. Eles produzirem algo sabe. Nossa foi muito bom. A aluna 1 (aluna com Transtorno do Espectro Autista), e a aluna 2 (Aluna com deficiência intelectual) ficaram interessadas, prestaram atenção o tempo todo. Elas receberam ajuda sim, mas foi pouco, mas para orientar qual material usar. Depois quando pedi para elas me descreverem o que elas fizeram, me emocionei muito. Elas souberam explicar o conceito de sistema respiratório. Era o que eu queria que elas soubessem.

A partir do relato de P5A, identificamos que o uso de estratégias diversificadas e o processo de planificação previsto na construção do protótipo promoveu uma aprendizagem significativa para seus alunos, em especial, àqueles com NEE. Destacamos que P5A valorizou a explicação oral por seus alunos do conceito de estudo com o apoio visual do material didático que foi confeccionado, pois alguns estudantes tiveram dificuldades para expressarem sua aprendizagem de modo escrito. Além disso, ao propor a construção do protótipo, forneceu mais uma opção de ação e expressão da aprendizagem que foi a esquematização dos conceitos de estudo.

Comumente, a finalidade da proposta curricular do DUA "[...] é o desenvolvimento de práticas pedagógicas que permitam o acesso ao currículo, à participação e ao progresso de todos os alunos, independentemente das suas capacidades" (MARIN, BRAUN, 2020, p. 14). Desse modo, essa abordagem curricular proposta pelo DUA vai em direção às diferenças e necessidades de todos os estudantes, em que os obstáculos pedagógicos são removidos para que haja acessibilidade curricular. Por isso, a diferenciação curricular pressupõe a promoção de equidade e frisa a importância de o currículo ser pensado de forma mais flexível, aberto às diferenças, orientado pelas singularidades dos estudantes e não pelas impossibilidades impostas ao processo de aprendizagem (NUNES, MADUREIRA, 2015; PRAIS, 2017).

No que se refere ao desenvolvimento do processo de formação, a partir do DUA, resumimos que a planificação dos princípios no planejamento de ensino e na prática pedagógica pelas professoras colaboradoras resultou na elaboração de atividades adequadas às necessidades de 
aprendizagem dos alunos com NEE, bem como, na utilização de recursos didáticos e materiais pedagógicos que favoreceram a melhoria na qualidade ensino para todos os alunos. Foram constatadas contribuições advindas do processo formativo por meio das mudanças ocorridas nos planos de aulas e nas práticas pedagógicas efetivas das docentes.

Interpretamos que o programa formativo subsidiado pelo DUA e aliado aos procedimentos da pesquisa colaborativa permitiu as professoras colaboradoras adentrar em suas práticas com olhar diferente, se distanciando para compreender, teorizando para interpretar as situações e ressignificando para guiar sua nova ação refletida. De acordo com a Ibiapina (2008), a reflexão entre teoria e prática promove a reconstrução da ação pedagógica de modo a aprimorá-la.

Análise dos dados da Fase 4: avaliação do processo de formação

Constatamos que as quatro professoras colaboradoras (P2A, P2B, P4A e P5A) ao final do processo de formação, sozinhas, sem auxílio da pesquisadora, conseguiram fazer a aplicação dos princípios do DUA, promovendo a inclusão dos alunos com NEE durante as suas aulas, como também conseguiram pensar em todos os alunos da turma, nas dificuldades e nas potencialidades de cada um.

Nesse sentido, na elaboração das atividades pedagógicas, que consideram os princípios norteadores do DUA, as possibilidades de aprendizado são ampliadas, pois a organização do ensino planifica tarefas adequadas ao atendimento das necessidades de aprendizagens dos alunos, ao tornar a aprendizagem mais acessível e, consequentemente, fortalece e assegura o direito de todos à educação (NUNES, MADUREIRA, 2015).

Tais indicativos puderam ser verificados em seus planejamentos e nas suas práticas em sala de aula, pois foram observadas diversas formas de apresentação do conteúdo, de possibilidades diversas de ação e expressão da aprendizagem pelos alunos e, de organização e incentivos para o interesse, o engajamento e a participação ativa dos alunos durante as aulas.

Sublinhamos as sugestões e críticas apresentadas pelas professoras colaboradoras, destacamos que solicitaram ampliar a proposta para rede municipal, envolvendo todas as escolas, bem como, contemplar as docentes da educação infantil que carecem de momentos formativos no que tange ao processo de inclusão.

Com relação as mudanças observadas no planejamento e na prática das professoras após o desenvolvimento da pesquisa, notamos o desenvolvimento profissional de cada uma das professoras colaboradoras a partir de planos de aula realizados de modo autônomo contemplando os princípios do DUA de modo adequando e refletida em uma prática pedagógica inclusiva, atendendo as necessidades de aprendizagem de todos os alunos da sala de aula.

\section{CONSIDERAÇÕES FINAIS}

De modo geral, os resultados reafirmam as potencialidades da formação colaborativa que promoveu efeito de mudança na atuação das professoras, bem como, evidenciaram a importância do DUA como conteúdo formativo para práxis inclusivas atendendo as necessidades vivenciadas pelas docentes em seu contexto de trabalho.

Evidenciamos que o aprimoramento do trabalho pedagógico desenvolvido pelas docentes em relação aos alunos com NEE se estendeu ao favorecimento da qualidade do ensino visando a aprendizagem de todos os estudantes.

Convém ressaltar que uma escola inclusiva nunca está totalmente edificada, pois ela se move, se constrói diária e colaborativamente com todos e com as ações de cada um, constitui-se 
em um processo de constante construção, mobilizada e comprometida com a formação dos estudantes e dos professores.

Acreditamos que tais resultados possam contribuir para construção de políticas públicas acerca da importância da inserção de conteúdos sobre o DUA nos cursos de formação de professores e, do desenvolvimento de políticas de formação de professores em serviço, baseadas no acompanhamento dos professores, de modo colaborativo com possibilidades de estudos e reflexões de forma coletiva no contexto de cada escola, para que suas necessidades específicas sejam contempladas.

E, nesse sentido, esta pesquisa reforça a necessidade da sensibilização e conscientização de todos os professores que atuam em cada instituição de ensino para construção de uma escola inclusiva de modo colaborativo, aliada a mobilização de ações visando à promoção da aprendizagem de todos. As trocas, a escuta e o engajamento são requisitos fundamentais para as concretizações de ações verdadeiramente inclusivas e formativas.

\section{REFERÊNCIAS}

BARDIN, Laurence. Análise de conteúdo. Lisboa, Portugal: Edições 70, 2011.

BRASIL. Constituição da República Federativa do Brasil. Brasília, DF: Senado, 1988.

CAPELLINI, Vera Lúcia Messias Fialho; FONSECA, Kátia de Abreu. A escola inclusiva: seus pressupostos e movimentos. Doxa - Revista Brasileira de Psicologia e Educação, v. 19, p. 107-127, 2017.

CAST. Universal Design for Learning Guidelines. Estados Unidos: Center for Applied Special Technology (CAST), 2011.

DÍEZ, Anabel Moriña. Traçando os mesmos caminhos para o desenvolvimento de uma educação inclusiva. Inclusão - Revista de Educação Especial, Brasília, v. 5, n. 1, p. 16-25, jan./jul. 2010.

HEREDERO, Eladio Sebastian. Escola inclusiva: um novo olhar para o currículo de uma escola para todos. Revista Eletrônica de Educação, v. 1, n. 1, p. 68-77, 2018.

IBIAPINA, Ivana Maria Lopes de Melo. Pesquisa colaborativa: investigação, formação e produção de conhecimentos. Brasília: Líber Livro, 2008.

LUSTOSA, Ana Valéria Marques Fortes. A expressão da subjetividade no contexto da educação inclusiva: complexidade e desafios. Obutchéne: Revista de Didática e de Psicologia e Pedagogia, Uberlândia, Minas Gerais, v. 5, n. 1, p. 114-134, jan./abr. 2019.

MARIN, Márcia; BRAUN, Patrícia. Currículo e diferenciação pedagógica: uma prática de exclusão? Revista Exitus, Santarém, Pará, v. 10, p. 1-27, 2020.

MEYER, Anna; ROSE, David; GORDON, David. Universal Design for Learning (UDL). Estados Unidos: CAST, 2002.

MEYER, Anna; ROSE, David; GORDON, David. Desenho Universal para a Aprendizagem: teoria e prática. Wake Field, MA: Elenco Professional Publishing, 2014.

MOURA, Manoel Oliveira. Pesquisa colaborativa: um foco na ação formadora. p. 257-284. In: BARBOSA, Raquel Lazzari Leite (org.). Trajetórias e perspectivas da formação de educadores. São Paulo: Unesp, 2004.

NUNES, Clarisse; MADUREIRA, Isabel Pissarro. Desenho Universal para a Aprendizagem: construindo práticas pedagógicas inclusivas. Revista Da investigação às práticas, v. 5, n. 2, p. 126-143, 2015. 
PRAIS, Jacqueline Lidiane de Souza. Das intenções à formação docente para a inclusão: contribuições do Desenho Universal para a Aprendizagem. Curitiba: Appris, 2017.

ROSA, Erica Aparecida Capasio. Escolas inovadoras e criativas e inclusão escolar: um estudo em educação matemática. Tese (Doutorado em Educação Matemática). Programa de Pós-graduação em Educação Matemática, Universidade Estadual Paulista Júlio de Mesquita Filho, Instituto de Geociências e Ciências Exatas, Rio Claro, 2019.

SANCHES, Isabel. Do "aprender para fazer" ao "aprender fazendo": as práticas de educação inclusiva na escola. Revista Lusófona de Educação, v. 19, n. 19, p. 135-156, 2011.

UNESCO. Declaração de Salamanca sobre princípios, politica e práticas na área das necessidades educativas especiais. Organização das Nações Unidas para a Educação, a Ciência e a Cultura. UNESCO: Salamanca, 1994.

VITALIANO, Celia Regina. Formação de professores de Educação Infantil para inclusão de alunos com necessidades educacionais especiais: uma pesquisa colaborativa. Revista Pro-Posições, v. 30, Campinas, jul. 2019.

Submetido em janeiro de 2020 Aprovado em abril de 2021

\section{Informações das autoras}

Jacqueline Lidiane de Souza Prais

Doutora em Educação pela Universidade Estadual de Londrina (UEL), docente no curso de Pedagogia da Universidade Estadual do Norte do Paraná (UENP).

E-mail: jacqueline_lidiane@hotmail.com

ORCID: https://orcid.org/0000-0002-3658-7021

Link Lattes: $\underline{\text { http://lattes.cnpq.br/5351398531043105 }}$

Celia Regina Vitaliano

Doutora em Educação pela Universidade Estadual Paulista Júlio de Mesquita Filho (UNESP) e docente no Programa de Pós-graduação em Educação (PPEdu) da Universidade Estadual de Londrina (UEL)

E-mail: reginavitaliano@gmail.com

ORCID: https://orcid.org/0000-0002-8757-4204

Link Lattes: http://lattes.cnpq.br/7209579954342576 